Check for updates

Cite this: RSC Adv., 2019, 9, 36940

Received 27th August 2019

Accepted 27th October 2019

DOI: $10.1039 / c 9 r a 06745 k$

rsc.li/rsc-advances

\section{Efficiencies and mechanisms of the chemical cleaning of fouled polytetrafluoroethylene (PTFE) membranes during the microfiltration of alkali/ surfactant/polymer flooding oilfield wastewater $\dagger$}

\author{
Bing Zhang, (D) *abc Shuili Yu, (D) ${ }^{d}$ Youbing Zhu, ${ }^{d}$ Yu Shen, ${ }^{\text {ab }}$ Xu Gao, ${ }^{\text {ab }}$ Wenxin Shi ${ }^{* e}$ \\ and Joo Hwa Tay ${ }^{\mathrm{C}}$
}

The chemical cleaning of fouled polytetrafluoroethylene (PTFE) membranes with different reagents after the microfiltration of alkali/surfactant/polymer (ASP) flooding oilfield wastewater was examined in this study. Foulant analyses, cleaning efficiencies of different reagents and conditions and cleaning mechanisms were investigated. The results showed that anionic polyacrylamide (APAM) and crude oil were the main membrane foulants accompanied by organic-inorganic-organic/membrane aggregate foulants formed by bridging inorganic ions and organic species. Cleaning efficiency of $93 \%$ was acquired through mixed cleaning with $0.04 \mathrm{~N} \mathrm{NaClO}+200 \mathrm{mg} \mathrm{L}^{-1} \mathrm{NaOH}$, which was found to be better than individual cleaning. Moreover, consecutive cleaning with $\mathrm{NaClO}+\mathrm{NaOH}-\mathrm{HCl}$ restored $98 \%$ of the membrane flux, suggesting that $\mathrm{HCl}$ cleaning contributed to flux recovery. Additionally, the cleaning temperature and time were set as $40^{\circ} \mathrm{C}$ and $3 \mathrm{~h}$, respectively, considering economy and membrane lifespan. Finally, the mechanism of membrane cleaning and analyses of membrane properties were described in this paper, aiming to provide a future direction for production practices. Considering that the cleaning reagents used in this study are easy to obtain and use, consecutive cleaning with $\mathrm{NaClO}+$ $\mathrm{NaOH}-\mathrm{HCl}$ is recommended to clean the PTFE membranes fouled by ASP flooding oilfield wastewater.

\section{Introduction}

In recent decades, alkali/surfactant/polymer (ASP) flooding oilfield wastewater is being increasingly produced during the oil recovery process. ${ }^{1-3}$ This wastewater needs to be processed prior to getting discharged into the environment to avoid the risk of severe pollution caused by its organic and inorganic components. ${ }^{1}$ Many countries that possess oilfields are seeking efficient and cost effective methods to manage this wastewater. ${ }^{4,5}$ In some oilfields, conventional techniques have been used to treat the wastewater; however, the emulsified and soluble oils in the wastewater cannot be effectively disposed. ${ }^{6}$

${ }^{a}$ National Base of International Science and Technology Cooperation for Intelligent Manufacturing Service, Chongqing Key Laboratory of Catalysis \& New Environmental Materials, Chongqing Technology and Business University, Chongqing 400067, China. E-mail: hitzhangbing@163.com

${ }^{b}$ Chongqing South-to-Thais Environmental Protection Technology Research Institute Co., Ltd., Chongqing 400060, China

'Department of Civil Engineering, University of Calgary, Calgary T2N 1N4, Canada

${ }^{d}$ School of Environmental Science and Engineering, State Key Laboratory of Pollution Control and Resource Reuse, Tongji University, Shanghai 200092, China

${ }^{e}$ School of Environmental and Ecology, Chongqing University, Chongqing 400044, China.E-mail:swx@hit.edu.cn

$\dagger$ Electronic supplementary information (ESI) available. See DOI: $10.1039 / \mathrm{c} 9 \mathrm{ra} 06745 \mathrm{k}$
Membrane separation has emerged as a promising alternative for oilfield wastewater treatment due to its superior properties, including good selectivity, strong adaptability, and chemical composition retention. ${ }^{-9}$ Microfiltration (MF) is considered to be one of the most effective membrane applications among the membrane separation processes for oilfield wastewater treatment. ${ }^{2,3,10}$ However, the $\mathrm{pH}$ of the wastewater has been observed to exceed the tolerable limit of commonly used MF membranes, which significantly shortens the membrane lifespan and increases operating costs. As an MF membrane, polytetrafluoroethylene (PTFE) is considered to be the best due to its high resistance to strong acids and alkalis, high and low temperatures, and corrosion. Thus, it is preferred for ASP flooding oilfield wastewater treatment., ${ }^{1,2,10-12}$ However, one of the obstacles impeding the large-scale development of MF is membrane fouling, which accounts for the decrease in membrane permeability or a rise in membrane resistance, resulting in the increase in operation costs and cleaning frequency. ${ }^{13}$ Although many methods have been adopted to prevent and alleviate membrane fouling, it remains inevitable during the MF process. ${ }^{14-18}$ Consequently, chemical cleaning becomes a necessary step in the MF process to resume the membrane flux and performance by removing foulants with chemical reagents. ${ }^{19-21}$ 
Thus, it is essential to select cost-effective chemical cleaning reagents, which are safe to use, do not produce new foulants, and most importantly do not damage the membrane. ${ }^{22}$ The commonly used inexpensive acids, bases, and oxidants cause some damage to normal MF membranes, while they cause little damage to the PTFE membranes., ${ }^{2,21}$ Zhao et al. ${ }^{23}$ immersed PTFE and polyvinylidene fluoride (PVDF) MF membranes in hydrochloric acid $(\mathrm{HCl})$, sodium hydroxide $(\mathrm{NaOH})$, hydrogen peroxide $\left(\mathrm{H}_{2} \mathrm{O}_{2}\right)$, and sodium hypochlorite ( $\left.\mathrm{NaClO}\right)$ solutions for $20 \mathrm{~d}, 40 \mathrm{~d}$, and $60 \mathrm{~d}$ at $40{ }^{\circ} \mathrm{C}$. The results showed that the PTFE membranes exhibited better resistance to chemicals compared to the PVDF membranes and maintained better membrane structural integrity.

Chemical reagents are generally divided into six categories: alkalis, acids, metal chelating agents, surfactants, oxidants, and enzymes. ${ }^{19,20} \mathrm{NaOH}$ is an alkaline cleaning agent, which can saponify fats and dissolve proteins to remove organic foulants, such as grease and pectin. ${ }^{24}$ Acidic cleaning agents, such as $\mathrm{HCl}$, nitric acid $\left(\mathrm{HNO}_{3}\right)$, oxalic acid, and citric acid, are mainly used to remove the oxides and hydroxides of calcium and magnesium as well as carbonates and silicates among others. ${ }^{19} \mathrm{NaClO}$ is a lowcost oxidant that is effective in cleaning large molecular foulants, such as polysaccharides and polymers. ${ }^{25}$ Metal chelating reagents, such as ethylenediaminetetraacetic acid (EDTA), can complex with inorganic ions in foulants to form highly soluble substances, thus reducing the fouling of the deposited salts and adsorbates. ${ }^{26}$ In addition, surfactants, such as sodium dodecyl sulfate (SDS), are used to remove organic foulants. ${ }^{27}$

The cleaning efficiencies of a membrane can be affected by individual cleaning reagents or combined cleaning reagents as well as cleaning conditions, which are determined by the properties of different cleaning reagents and their reaction mechanisms with membrane foulants. ${ }^{28}$ The changes in the quality of raw wastewater can also lead to different membrane fouling situations. ${ }^{29}$ For example, recent studies have shown that the composition of membrane foulants is significantly different during seawater desalination and wastewater reuse. ${ }^{30}$ Recently, some studies reported the chemical cleaning of MF membranes. ${ }^{21,31-33}$ However, many of these studies focused on optimizing the concentration of cleaning reagents, reaction time, and temperature. Research on consecutive cleaning with chemical reagents, especially the cleaning mechanisms for the PTFE membranes used in ASP flooding oilfield wastewater treatments, is lacking.

The main goal of this study was to determine the composition of membrane foulants, investigate the appropriate chemical reagents and their cleaning efficiencies, and discuss the involved cleaning mechanisms of the foulants disengaged from the membrane. The findings from this study can help in resolving the issues related to the chemical cleaning of MF membranes for ASP flooding oilfield wastewater treatment.

\section{Materials and methods}

\subsection{The flat membrane module}

The flat membrane module used in this study is shown in Fig. 1, and its characteristics are listed in Table 1.

\subsection{Experimental apparatus}

The schematic of the experimental apparatus is shown in Fig. 1. It mainly consisted of a raw wastewater tank of volume $0.06125 \mathrm{~m}^{3}$, a membrane tank of volume $0.018 \mathrm{~m}^{3}$, an effluent tank, constant flow pumps, pressure transducers, and a data acquisition system. The flat membrane modules were vertically put in the membrane tank, which was installed inside the raw wastewater tank. The permeate was sucked from the raw wastewater tank by constant flow pumps (BT600-2J, Longer, China). The transmembrane pressure (TMP) was monitored by pressure transducers (PTP708, Tuopo Electric, Foshan, China), and the data were constantly recorded by a data acquisition software (Siemens).

\subsection{Composition of the raw wastewater}

The raw wastewater was obtained from an oil production plant in Daqing, China, and its composition is shown in Table S1. $\dagger$ The raw wastewater contained a mass of anionic polyacrylamide (APAM) with the concentration of $749 \pm 33 \mathrm{mg} \mathrm{L}^{-1}$, which was used as oil displacement. It also contained organic matter in large quantity, suspended solids (SS), and salts, with the concentrations of $1083 \pm 65 \mathrm{mg} \mathrm{L}^{-1}$ of COD, $83 \pm 17 \mathrm{mg} \mathrm{L}^{-1}$ of SS, and $5984 \pm 450 \mathrm{mg} \mathrm{L}{ }^{-1}$ of TDS, respectively, which might have caused serious fouling on the PTFE membrane. In addition, the $\mathrm{pH}$ and temperature of the raw wastewater were $12.6 \pm$ 0.3 and $40 \pm 0.7^{\circ} \mathrm{C}$, respectively.

\subsection{Membrane fouling and cleaning}

The operating parameters (operating flux, backwashing flux, and intensity of gas washing) of MF experiments were kept consistent to subject the membranes to the same degree of fouling. Additionally, MF processes were not terminated until the TMP reached a predetermined value $(70 \mathrm{kPa})$. At the end of the experiments, $\mathrm{NaOH}, \mathrm{NaClO}, \mathrm{HCl}, \mathrm{HNO}_{3}, \mathrm{SDS}$, and EDTA solutions with a concentration of $0.5 \%$ (wt $\%$ ) were used separately for immersion at $40{ }^{\circ} \mathrm{C}$ for $3 \mathrm{~h}$ to chemically clean the fouled PTFE membrane used for ASP flooding oilfield wastewater treatment. Based on preliminary screening, $\mathrm{NaClO}(0.01-$ $0.05 \mathrm{~N}), \mathrm{NaOH}\left(50-250 \mathrm{mg} \mathrm{L}^{-1}\right)$, and $\mathrm{HCl}(0.1-1 \%)$ were selected as chemical cleaners for follow-up studies. Furthermore, the effects of cleaning sequence $(\mathrm{NaClO}+\mathrm{NaOH}-\mathrm{HCl}$ or $\mathrm{HCl}-\mathrm{NaClO}$ $+\mathrm{NaOH})$, temperature $\left(20-50{ }^{\circ} \mathrm{C}\right)$, and time $(0.5-5 \mathrm{~h})$ on the cleaning efficiencies were also investigated. After each cleaning cycle, deionized water was filtered again to determine the flux recovery (FR); the calculation process used is shown in eqn (1).

$$
\mathrm{FR}=\frac{J_{\text {clean }}-J_{\text {fouled }}}{J_{\text {raw }}-J_{\text {fouled }}}
$$

Here, $J_{\text {clean }}, J_{\text {fouled }}$, and $J_{\text {raw }}$ are the membrane fluxes of the same membrane (or the same membrane module) in its original state, after fouling, and after cleaning, respectively, with the unit $\mathrm{L} \mathrm{m}^{-2} \mathrm{~h}^{-1}$

\subsection{Analytical methods}

The micromorphology of the membrane surface was observed and photographed by scanning electron microscopy (SEM, S- 


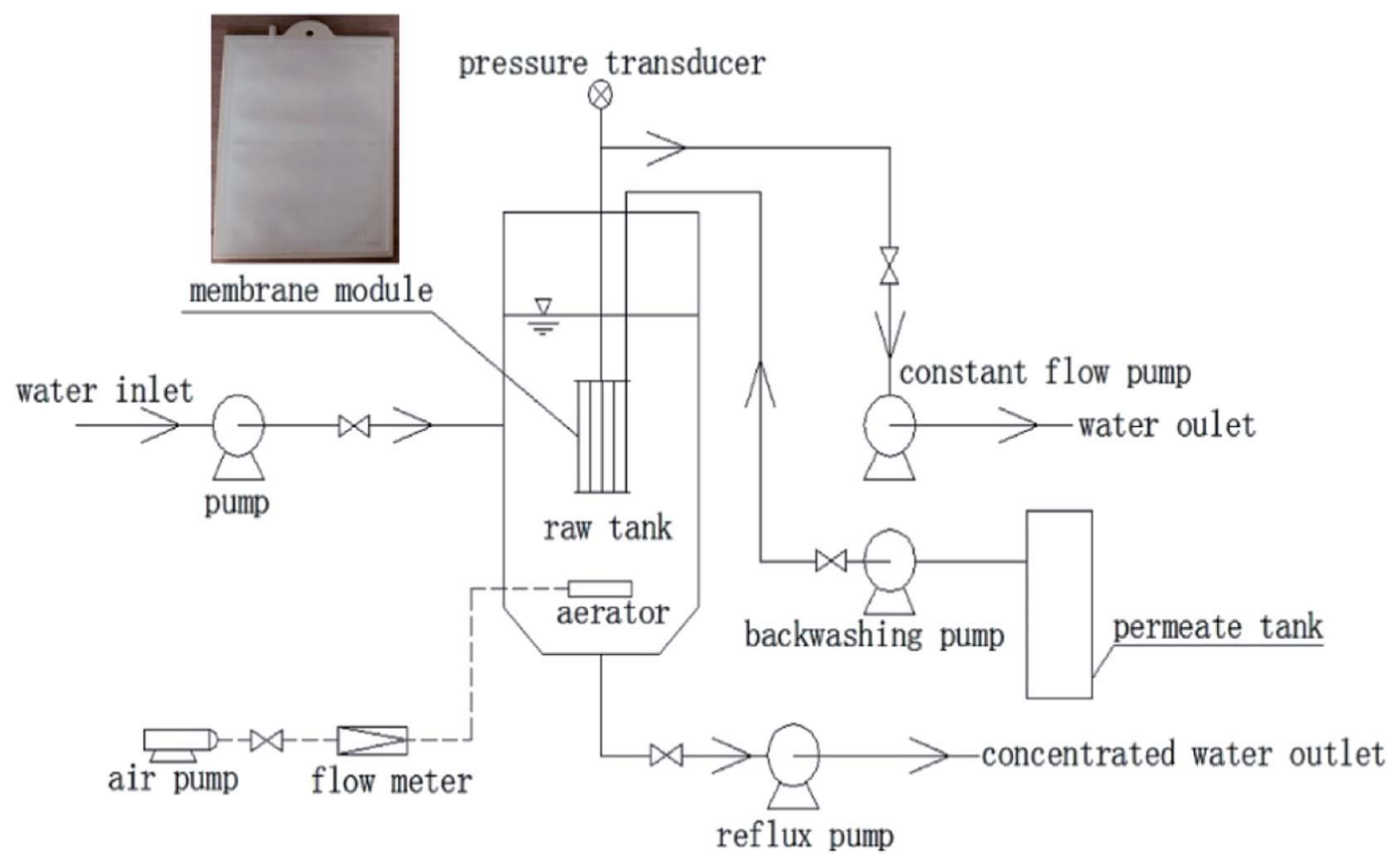

Fig. 1 The schematic of the experimental apparatus.

4800, Hitachi, Japan), and the main metal and non-metal elements on the fouled layer of the membrane surface were qualitatively evaluated using the energy dispersive X-ray spectrometer (EDX) on SEM. To retain the spatial morphology of the membrane to the maximum extent possible, the membranes were dried to a freezing state. Before observing the membrane sample, a conductive layer of gold, of approximately $2 \mathrm{~nm}$ thickness, was plated on the membrane surface by sputtering (Gatan, USA). ${ }^{1}$

The functional groups on PTFE membranes were observed by Fourier transform infrared spectroscopy (FTIR, Nicolet 560, Thermo Electron Corp., USA), and the measured wavenumber range was $4000-650 \mathrm{~cm}^{-1} .^{34}$

\section{Results and discussion}

\subsection{Foulant analyses}

EDX scanning was performed on the surface of PTFE membranes, as shown in Fig. 2. The mass percentages of the elements found on the membranes are listed in Table S2. $\uparrow \mathrm{C}, \mathrm{O}$, and $\mathrm{F}$ were found to be the basic elements of the PTFE membrane, of which $\mathrm{C}$ and $\mathrm{F}$ came from the framework of the membrane and $\mathrm{O}$ belonged to the hydrophilic groups. The contents of $\mathrm{C}$ and $\mathrm{O}$ on the fouled membrane compared to that for the original membrane were observed to increase from $36.35 \%$ to $42.60 \%$ and $8.42 \%$ to $11.51 \%$, respectively; the content of $\mathrm{F}$ significantly decreased from $55.23 \%$ to $21.36 \%$. This indicated that the PTFE membrane was covered by many organic foulants, which may be crude oil, APAM, and surfactants contained in the raw wastewater. Furthermore, many inorganic elements appeared on the fouled membrane. The APAM molecules in the wastewater are negatively charged due

to their ionized carboxyl groups. Therefore, positively charged metal ions can bind to the APAM molecules via electrostatic attraction and complexation bridging. ${ }^{35}$ Another possibility is that the alkalinity of ASP flooding oilfield wastewater was relatively high because it contained a large amount of $\mathrm{OH}^{-}$ions, which might have resulted in the formation of inorganic precipitates, such as $\mathrm{Fe}(\mathrm{OH})_{3}, \mathrm{Ca}(\mathrm{OH})_{2}$, and $\mathrm{Mg}(\mathrm{OH})_{2}$.

The FTIR spectra of the PTFE membranes are represented in Fig. 3. The infrared absorption spectra of the fouled membrane show several new absorption peaks compared to that of the original membrane, where the peak at $3285 \mathrm{~cm}^{-1}$ represents the $\mathrm{N}-\mathrm{H}$ bond of amide species, revealing that APAM assembled on the membrane surface. ${ }^{1}$ Furthermore, the observed absorption peaks of the $\mathrm{C}-\mathrm{H}$ bond of alkanes, $\mathrm{C}=\mathrm{C}$ bond of olefins, and methylene groups appeared at $2923 \mathrm{~cm}^{-1}, 1641 \mathrm{~cm}^{-1}$, and $1412 \mathrm{~cm}^{-1}$, respectively, suggesting the presence of crude oil on the fouled membrane. ${ }^{36}$ The results obtained here were consistent with those of EDX analyses, implying that APAM and crude oil were the main membrane foulants.

Table 1 Parameters and characteristics of the flat membrane module

Parameter Value

Texture of the membrane Texture of the support layer Manufacturer Average pore diameter $(\mu \mathrm{m})$ Effective length and width $(\mathrm{cm})$ Zeta potential $(\mathrm{mV})$

Contact angle $\left(^{\circ}\right)$
PTFE

Polyethylene terephthalate (PET) VALQUA Industries (Japan) 0.1 $28 \times 18$

$-22.1$

120.1 

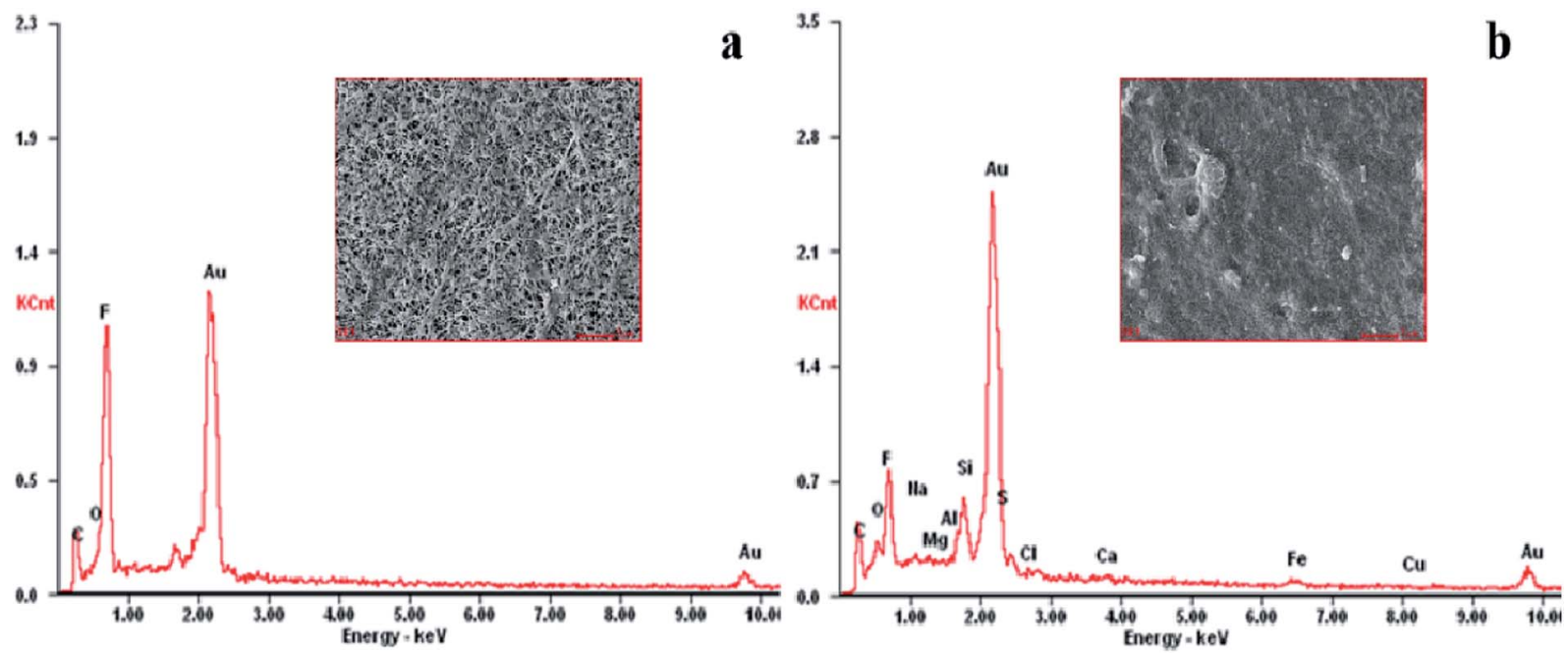

Fig. 2 EDX analyses of the (a) original membrane and (b) fouled membrane.

\subsection{Comparison of the cleaning efficiencies among different reagents}

The membrane fouling of the PTFE membranes used for ASP flooding oilfield wastewater treatment involves a combination of organic and inorganic species with regards to the type of foulants. Moreover, the foulants and the membranes are closely bound by complexation and hydrogen bonding. On-line physical cleaning (backwashing, aeration, etc.) is found to be difficult to completely restore the membrane performance; therefore, chemical cleaning with acids, bases, surfactants, metal chelators, and oxidants is required to remove the foulants that are difficult to wipe off the membrane surface.

3.2.1 Cleaning efficiencies of different individual reagents. The fouled membrane was chemically cleaned by immersing it in $\mathrm{NaOH}, \mathrm{NaClO}, \mathrm{HCl}, \mathrm{HNO}_{3}$, SDS, and EDTA solutions with a finite concentration at $40{ }^{\circ} \mathrm{C}$ for $3 \mathrm{~h}$. The flux recoveries with different individual reagents are shown in Fig. 4a. It was observed that these six cleaning reagents could restore the membrane flux, while the $\mathrm{HNO}_{3}$ solution exhibited the worst cleaning efficiency with a flux recovery of only $44.68 \%$. The cleaning results of the $\mathrm{HCl}$, SDS, and EDTA solutions were found to be normal, with the flux recoveries of $52.71 \%, 49.37 \%$, and $47.32 \%$, respectively. Additionally, the cleaning effects of the $\mathrm{NaClO}$ and $\mathrm{NaOH}$ solutions were observed to be particularly prominent, with the flux recovery greater than $70 \%$. $\mathrm{NaOH}$ and $\mathrm{NaClO}$ have been noted to saponify fats and dissolve polymers to remove organic foulants. ${ }^{\mathbf{2 4 , 2 5}}$ However, they are not known to be effective in removing inorganic foulants and metalcontaining deposits. ${ }^{37,38}$ In this study, it was proven that organic fouling was more serious than inorganic fouling on the membrane surface, which is consistent with the conclusion reported in Section 3.1.

Furthermore, the NaClO solution exhibited a better cleaning performance compared to the $\mathrm{NaOH}$ solution, which was consistent with the results reported by Ahmad et al. ${ }^{39}$ and Zhang et $a .^{40}$ Zhen et $a l .{ }^{41}$ adopted $\mathrm{NaOH}$, SDS, EDTA, HCl, citric acid, and oxalic acid to chemically clean the ultrafiltration membrane treated with oilfield produced water, and the results indicated that $\mathrm{NaOH}$ exhibited the best cleaning efficiency. Since the cleaning efficiency of the NaClO solution was not studied, no direct comparison can be drawn with the results of this experiment. Additionally, Wei et $a .^{42}$ and Grélot et al. ${ }^{43}$ confirmed that $\mathrm{NaClO}$ exhibited the best results for flux recovery among all tested cleaning agents (e.g., $\mathrm{NaOH}, \mathrm{HCl}$, citric acid, and EDTA). Furthermore, the cleaning efficiency of alkalis was found to be better than that of acids since the membrane foulants were mainly organic, which was consistent with the results by Norazman et al. $^{44}$

It was also observed that individual cleaning reagents could not completely remove all membrane foulants; thus, they could not achieve efficient cleaning. Therefore, $\mathrm{NaClO}, \mathrm{NaOH}$, and $\mathrm{HCl}$ solutions with better cleaning effects were selected as the chemical cleaning reagents in the following study. They were mixed for the consecutive cleaning of fouled membranes to

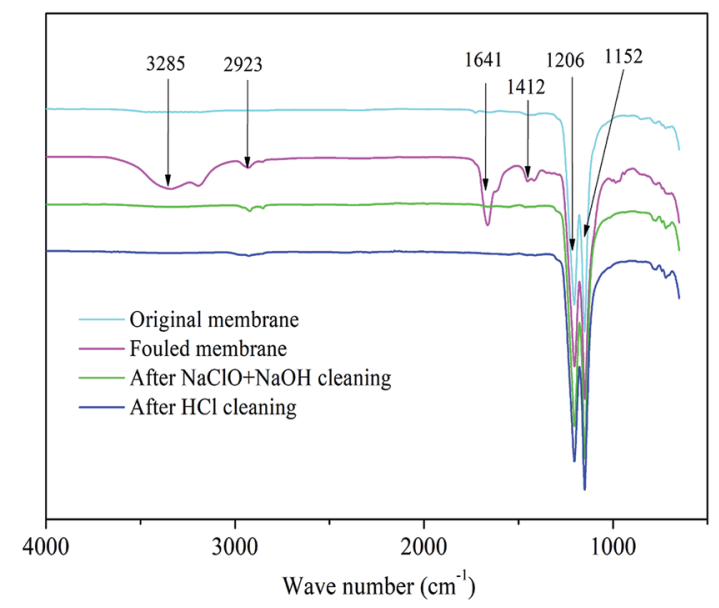

Fig. 3 FTIR spectra of various PTFE membranes. 

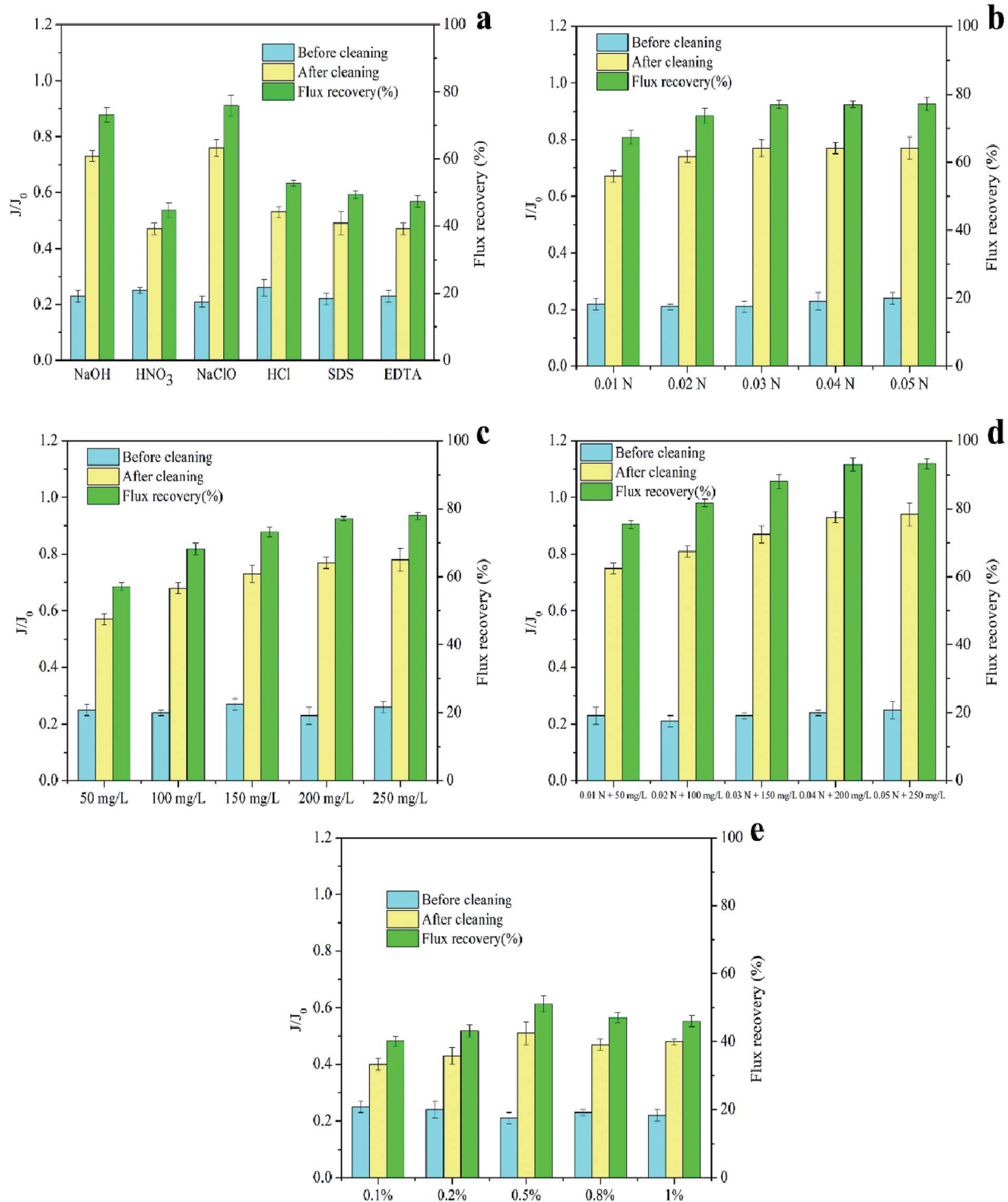

Fig. 4 Cleaning efficiencies of different cleaning reagents (a), $\mathrm{NaClO}$ solutions with different concentrations (b), $\mathrm{NaOH}$ solutions with different concentrations (c), $\mathrm{NaClO}+\mathrm{NaOH}$ mixed solutions with different concentrations (d), and $\mathrm{HCl}$ solutions with different concentrations (e).

obtain higher flux recovery and regeneration of the fouled membranes.

3.2.2 Cleaning efficiencies of NaClO solutions. The cleaning efficiencies of $\mathrm{NaClO}$ solutions having different concentrations for the fouled membrane are shown in Fig. 4b. The flux recoveries were observed to increase from $67.33 \pm 2.13 \%$ to
$77.23 \pm 1.93 \%$ on increasing the NaClO concentrations. Furthermore, when an MF membrane, fouled by microalgae biomass, was chemically cleaned, the NaClO solution exhibited an excellent cleaning effect. ${ }^{45} \mathrm{NaClO}$, as a commonly used oxidant, oxidizes the functional groups of organic foulants into ketones, aldehydes, and carboxylic acids to remove organic 
foulants, especially APAM. ${ }^{28}$ APAM was one of the major membrane foulants (Section 3.1), which interacted with NaClO. The process of the interaction is expressed in eqn (2)-(6), which can be summarized into three stages: (a) chlorination of the nitrogen atoms in amide groups; (b) separation of hydrogen ions and rearrangement of the $\mathrm{N}-\mathrm{Cl}$ anions; and (c) conversion of formyl groups into amino groups in polymers. ${ }^{46}$
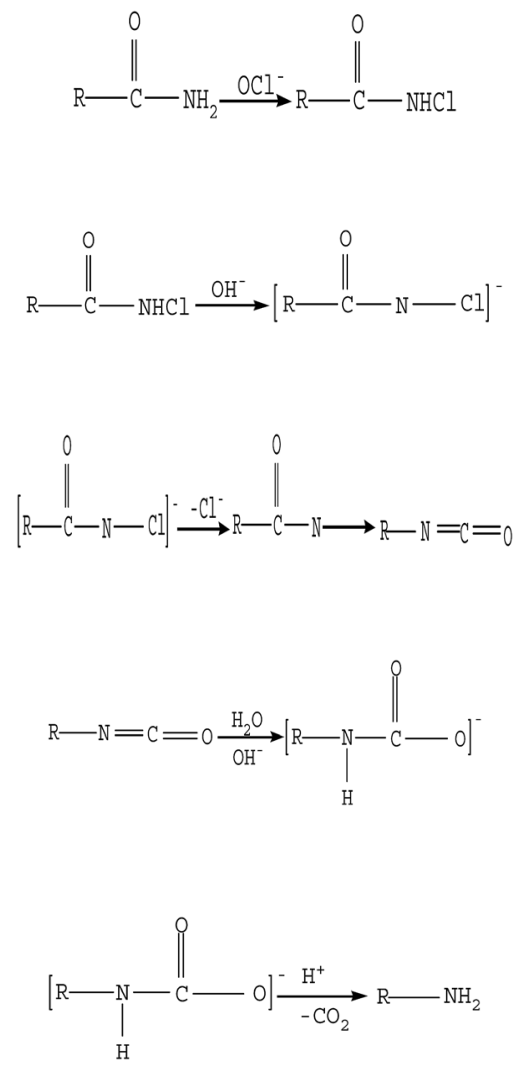

3.2.3 Cleaning efficiencies of $\mathrm{NaOH}$ solutions. The flux recoveries were observed to increase to $57.16 \%, 68.22 \%$, $73.16 \%, 77.12 \%$, and $77.89 \%$ on increasing the $\mathrm{NaOH}$ concentrations to $50 \mathrm{mg} \mathrm{L}^{-1}, 100 \mathrm{mg} \mathrm{L}^{-1}, 150 \mathrm{mg} \mathrm{L}^{-1}, 200 \mathrm{mg} \mathrm{L}^{-1}$, and $250 \mathrm{mg} \mathrm{L}^{-1}$, respectively, as shown in Fig. 4c. It removed the organic foulants on the membrane through hydrolysis and solubilization. The hydroxide ions in the alkaline solution promoted the disintegration of the fouled layer mainly by breaking the chemical bonds between the membrane and foulants. ${ }^{28}$ Moreover, the alkali reacted with crude oil by saponification to form water-soluble micelles. ${ }^{47}$ During the cleaning process, $\mathrm{NaOH}$ primarily acted as a bulking agent and protein solubilizer. The carboxyl groups and the phenolic substances were deprotonated by increasing the solubility and $\mathrm{pH}$ of the solution, thus increasing the negative charge of the organic foulants and causing repulsion with the PTFE membrane, which resulted in the separation of the foulants from the membrane..$^{\mathbf{4 8 , 4 9}}$

3.2.4 Cleaning efficiencies of $\mathrm{NaClO}+\mathrm{NaOH}$ mixed solutions. Fig. $4 \mathrm{~d}$ shows that the cleaning efficiencies of the $\mathrm{NaClO}$ and $\mathrm{NaOH}$ mixture with the flux recovery of $93.23 \%$ at a concentration of $0.05 \mathrm{~N} \mathrm{NaClO}+250 \mathrm{mg} \mathrm{L}^{-1} \mathrm{NaOH}$ are superior to their individual cleaning efficiencies. Mixing $\mathrm{NaClO}$ and $\mathrm{NaOH}$ substantially increased the membrane flux to $150 \%$ compared to being cleaned individually with $\mathrm{NaClO}(60 \%)$ and $\mathrm{NaOH}(<10 \%) .{ }^{47}$ This was because $\mathrm{NaOH}$ changed the configuration of the organic foulants on the membrane and loosened the fouled layer through hydrolysis and solubilization. ${ }^{47}$ Moreover, our previous studies confirmed that APAM could cause a "shield effect" on crude oil fouling on the PTFE membrane, which implied that APAM was closely bound to the membrane, while the crude oil was present above the APAM fouling layer. ${ }^{35}$ In such a case, the membrane outer fouling layer was first attacked with the $\mathrm{NaOH}$ solution, which then allowed $\mathrm{NaClO}$ to react with the innermost APAM relatively easily. ${ }^{50}$ Additionally, little difference was observed in the flux recoveries between the solutions of $0.04 \mathrm{~N} \mathrm{NaClO}+200 \mathrm{mg} \mathrm{L}^{-1} \mathrm{NaOH}$ and $0.05 \mathrm{~N}$ $\mathrm{NaClO}+250 \mathrm{mg} \mathrm{L}^{-1} \mathrm{NaOH}$, both of which were found to be above $93 \%$. Considering the expense and membrane lifespan, it was considered more suitable to adopt the concentration of $0.04 \mathrm{~N} \mathrm{NaClO}+200 \mathrm{mg} \mathrm{L}^{-1} \mathrm{NaOH}$.

3.2.5 Cleaning efficiencies of $\mathrm{HCl}$ solutions. The cleaning efficiencies of different concentrations of $\mathrm{HCl}$ solutions on fouled membranes are depicted in Fig. 4e. The removal targets of the $\mathrm{HCl}$ solution were the inorganic foulants on the fouled membrane. Here, the inorganic foulants included scaling substances, such as $\mathrm{CaCO}_{3}, \mathrm{Mg}(\mathrm{OH})_{2}, \mathrm{SiO}_{2}$, and $\mathrm{Fe}$ oxides, accumulated on the membrane during long-term operation. They also included high-valent metal ions that combined with organics (mainly carboxylic acid groups, sulfonic acid groups, etc.) by forming ionic bonds. The latter played a crucial bridging role in the formation and development of fouling layers on the membrane, especially the gel layer. ${ }^{51-53} \mathrm{Al}$-amoudi et al. ${ }^{49}$ verified that the flux of a membrane cleaned with an $\mathrm{HCl}$ solution $\left(9.2 \mathrm{~kg} \mathrm{~m}^{-2} \mathrm{~h}^{-1}\right)$ was higher than that of the membrane cleaned without an $\mathrm{HCl}$ solution $\left(5.6 \mathrm{~kg} \mathrm{~m}^{-2} \mathrm{~h}^{-1}\right)$. When the concentration of the $\mathrm{HCl}$ solution was $<0.5 \%$, the flux recoveries were observed to increase from $40.16 \%$ to $52.71 \%$ on increasing the concentrations of the $\mathrm{HCl}$ solution. However, when the concentrations of the $\mathrm{HCl}$ solution increased above $0.5 \%$, the flux recoveries showed a decreasing trend. This might be due to the reaction between cleaning reagents and foulants during the cleaning process, which produced some by-products and caused secondary fouling of the membrane. ${ }^{54}$

\subsection{Cleaning efficiencies under different conditions}

The flux recovery is not only affected by the type and the concentration of the cleaning reagent, but is also restricted by the cleaning conditions, such as the sequence, temperature, and time. ${ }^{28}$ Therefore, this section focuses on the effect of different cleaning conditions on flux recoveries.

3.3.1 Effect of sequence on cleaning efficiencies. To improve the efficiency of chemical cleaning, cleaning reagents are often used sequentially, and the cleaning sequence impacts the flux recovery. In this study, fouled membranes were cleaned with the sequence $\mathrm{HCl}(0.5 \%)-\mathrm{NaClO}+\mathrm{NaOH}(0.04 \mathrm{~N}+$ $200 \mathrm{mg} \mathrm{L}^{-1}$ ) and $\mathrm{NaClO}+\mathrm{NaOH}-\mathrm{HCl}$ within $3 \mathrm{~h}$ of cleaning with the cleaning duration of each section being $1.5 \mathrm{~h}$. The cleaning 
efficiencies are shown in Fig. 5. The final cleaning efficiency of the fouled membrane after $3 \mathrm{~h}$ for the cleaning sequence $\mathrm{NaClO}$ $+\mathrm{NaOH}-\mathrm{HCl}$ was found to be $99.12 \%$, while for the cleaning sequence $\mathrm{HCl}-\mathrm{NaClO}+\mathrm{NaOH}$, it was $94.22 \%$. It is important to note that carrying out $\mathrm{NaClO}+\mathrm{NaOH}$ cleaning first helped in destroying the configuration of the fouling layer and removing the organic foulants in large quantity. Thereafter, the residual metal ions formed due to bridging were removed by $\mathrm{HCl}$ cleaning. Afterwards, the organic foulants connected with them fell off from the membrane, thus improving the efficiency of the subsequent $\mathrm{HCl}$ cleaning. In contrast, when the fouled membrane was first cleaned with the $\mathrm{HCl}$ solution, the compact fouling layer was not easily destroyed by the $\mathrm{HCl}$ solution since it could only elute some inorganic scaling substances. Thus, the flux recovery would have been essentially consistent with that of $\mathrm{NaClO}+\mathrm{NaOH}$ cleaning. Wang et al. ${ }^{28}$ proved that the cleaning efficiency of consecutive NaClO-citric cleaning was higher than that of the reverse method.

3.3.2 Effect of temperature and time on cleaning efficiencies. Consecutive cleaning with $\mathrm{NaClO}+\mathrm{NaOH}-\mathrm{HCl}$ was carried out to study the cleaning performance at different cleaning temperatures and times on the fouled membrane, as shown in Fig. 6. It has been shown that the reaction kinetics of the oxidation process and the solubility of the foulants or reaction products as well as the distribution of reagents in a polymer matrix increase on increasing the temperature. ${ }^{28}$ The flux recoveries were found to be $85.16 \%, 93.22 \%, 98.44 \%$, and $99.13 \%$ at the cleaning temperatures of $20{ }^{\circ} \mathrm{C}, 30{ }^{\circ} \mathrm{C}, 40{ }^{\circ} \mathrm{C}$, and $50{ }^{\circ} \mathrm{C}$, respectively. Zhang et al. ${ }^{55}$ showed that an increase in temperature was beneficial to the recovery of membrane flux when conducting chemical cleaning of a fouled membrane while treating the wastewater of a banknote printing factory. Bartlett et $a .^{56}$ found that for two types of membranes, the recoveries of membrane flux increased as the temperature increased from $30{ }^{\circ} \mathrm{C}$ to $50{ }^{\circ} \mathrm{C}$ under the optimal concentrations of cleaning reagents. However, as the temperature increased, different cleaning reagents performed differently for the MF

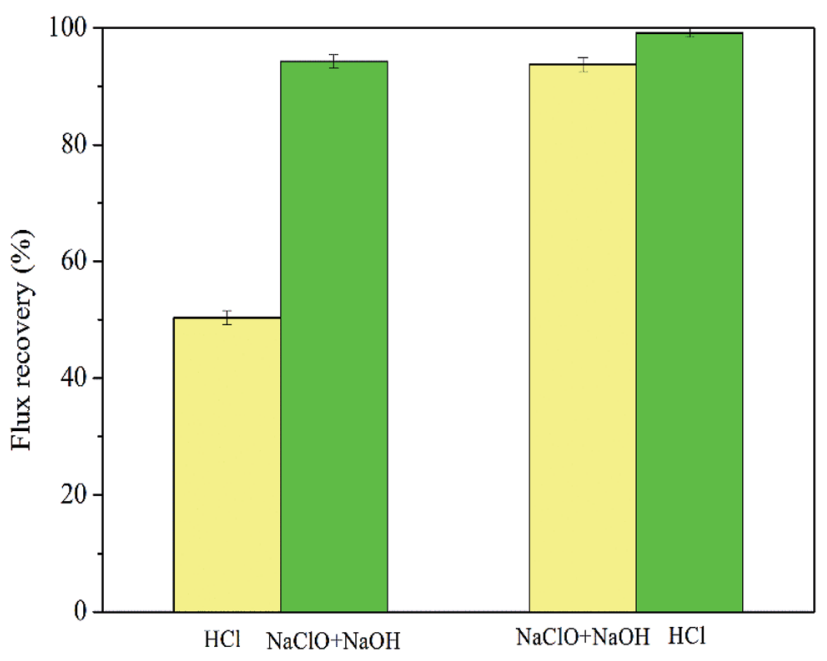

Fig. 5 Effect of the cleaning sequence on cleaning efficiencies. membrane cleaning. For instance, a commercial cleaner (SurfactronCD50) did not significantly affect flux recoveries at temperatures above $45{ }^{\circ} \mathrm{C} .{ }^{57}$ Therefore, it was reasonable to choose the cleaning temperature of $40{ }^{\circ} \mathrm{C}$ in this study.

The flux recoveries were found to be $73.16 \%, 76.23 \%$, $90.98 \%, 98.47 \%$, and $98.24 \%$ at the cleaning times of $0.5 \mathrm{~h}, 1 \mathrm{~h}$, $2 \mathrm{~h}, 3 \mathrm{~h}$, and $5 \mathrm{~h}$, respectively, indicating that the cleaning efficiencies improved with an extension in cleaning time. However, little difference was noted in the cleaning efficiencies at the cleaning times of $3 \mathrm{~h}$ and $5 \mathrm{~h}$. This was because the prolonged cleaning time could only remove the foulants loosely bound to the membrane during the cleaning process and could not elute the foulants tightly adsorbed on the membrane. ${ }^{21}$ Furthermore, much longer immersion of the membrane in chemical cleaning reagents showed a definite impact on its properties and structure, and shortening the cleaning time helped in extending its lifespan. Thus, setting the cleaning time to $3 \mathrm{~h}$ was proven to be more appropriate.

\subsection{Proposed mechanism of chemical cleaning}

3.4.1 SEM-EDX analysis. The morphology and structure of the PTFE membranes are depicted in Fig. 7. The surface of the original membrane was relatively flat but rough with irregular membrane pores (Fig. 7a). After the MF experiments, the membrane surface was covered with a bumpy gel layer, with most of the membrane pores being blocked (Fig. 7b). However, after $1.5 \mathrm{~h}$ of cleaning with $0.04 \mathrm{~N} \mathrm{NaClO}+200 \mathrm{mg} \mathrm{L}^{-1} \mathrm{NaOH}$, most foulants on the membrane surface were removed (Fig. 7c). According to Table $\mathrm{S} 2, \uparrow$ some metal ions and organics remain on the membrane surface, which might be due to metal ions attaching organic foulants to the membrane through bridging (Section 3.3.1). After $1.5 \mathrm{~h}$ of cleaning with $0.8 \% \mathrm{HCl}$, the surface morphology of the membrane surface mostly recovered to being smooth and flat, and the membrane pores were clearly visible (Fig. 7d). Additionally, the foulants on the membrane surface were mostly eliminated (Table S2 $\dagger$ ).

3.4.2 FTIR analysis. It can be observed from Fig. 3 that the spectral waveform of the membrane cleaned with $\mathrm{NaClO}+$ $\mathrm{NaOH}$ is essentially the same as that of the original membrane, indicating that a large proportion of the foulants was eluted and only a very small amount of crude oil remained on the membrane $\left(2923 \mathrm{~cm}^{-1}\right)$. Subsequently, after HCl cleaning of the metal ionic bonds on the membrane, the cleaned membrane looked new and closely resembled the original membrane, which is consistent with the previous results on flux recoveries and SEM (Sections 3.2.5 and 3.4.1), indicating that the cleaning method is very efficient.

3.4.3 Analyses of the membrane properties. The properties of the PTFE membranes obtained before and after chemical cleaning during the five cleaning cycles are displayed in Fig. 8. The determination of the contact angle (CA) is one of the methods used to analyze the characteristic changes in the membrane surface, which reflect the hydrophilicity/ hydrophobicity of the membrane. ${ }^{35}$ Compared to CA of the original membrane, the CA of the fouled membrane became larger, indicating that the uppermost layer of the membrane 

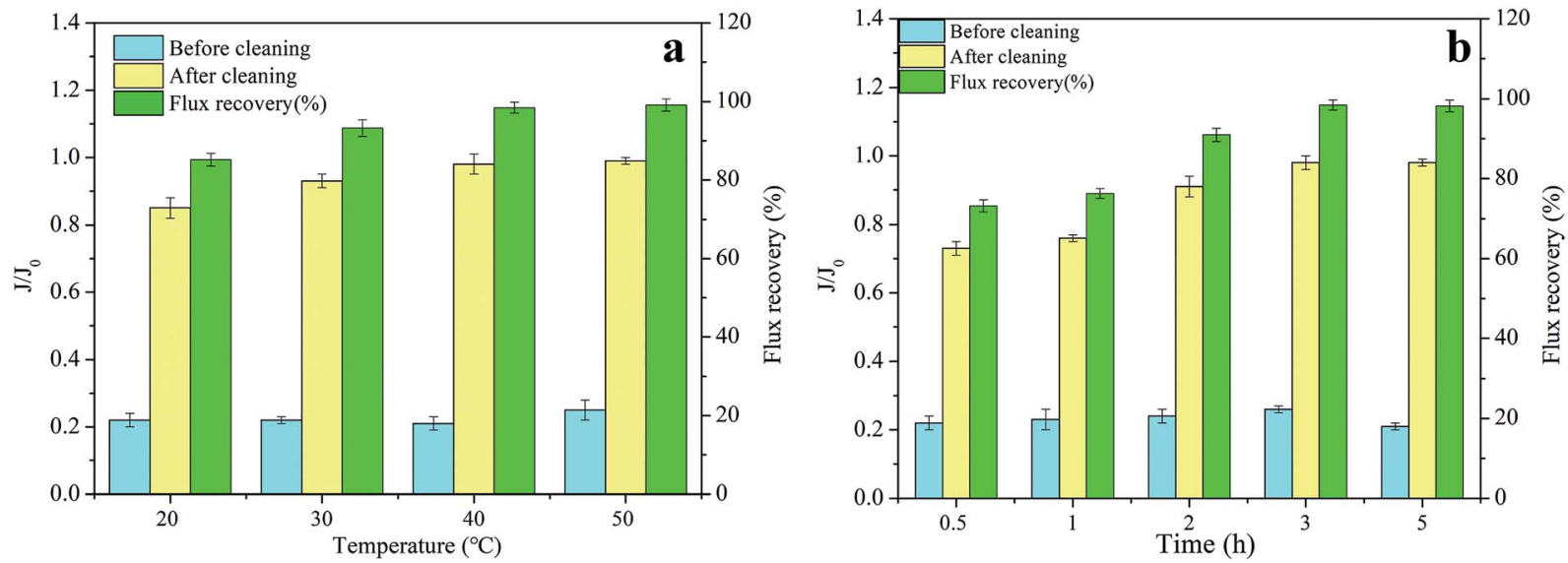

Fig. 6 Effect of the cleaning temperature (a) and time (b) on cleaning efficiencies.

foulants might consist of hydrophobic materials. According to the composition of raw wastewater (Table S1 $\dagger$ ), it was speculated that the top of the fouling layer consisted of crude oil, which is consistent with our previous study. ${ }^{35}$ Furthermore, CA of the PTFE membrane after chemical cleaning under optimum conditions was found to be similar to that of the original membrane (Fig. 8a). It should be especially noted that as the usage time of the membrane increased, irreversible fouling continued to accumulate, resulting in a decrease in the membrane performance. Moreover, repeated cleaning and longterm contact with chemical cleaning reagents would have damaged the membrane structure, increased the pore sizes, and reduced the tensile strength, leading to the failure of stable operation for the membrane reactor as expected by the design (e.g., the quality and yield of the effluent could not meet the design requirements). In addition to $\mathrm{CA}$, the pore size and tensile strength of the cleaned membrane were not found to be significantly different from that of the original membrane (Fig. $8 \mathrm{~b}$ and c), which illustrated that the chemical properties of the PTFE membrane were relatively stable during the treatment of ASP flooding oilfield wastewater.

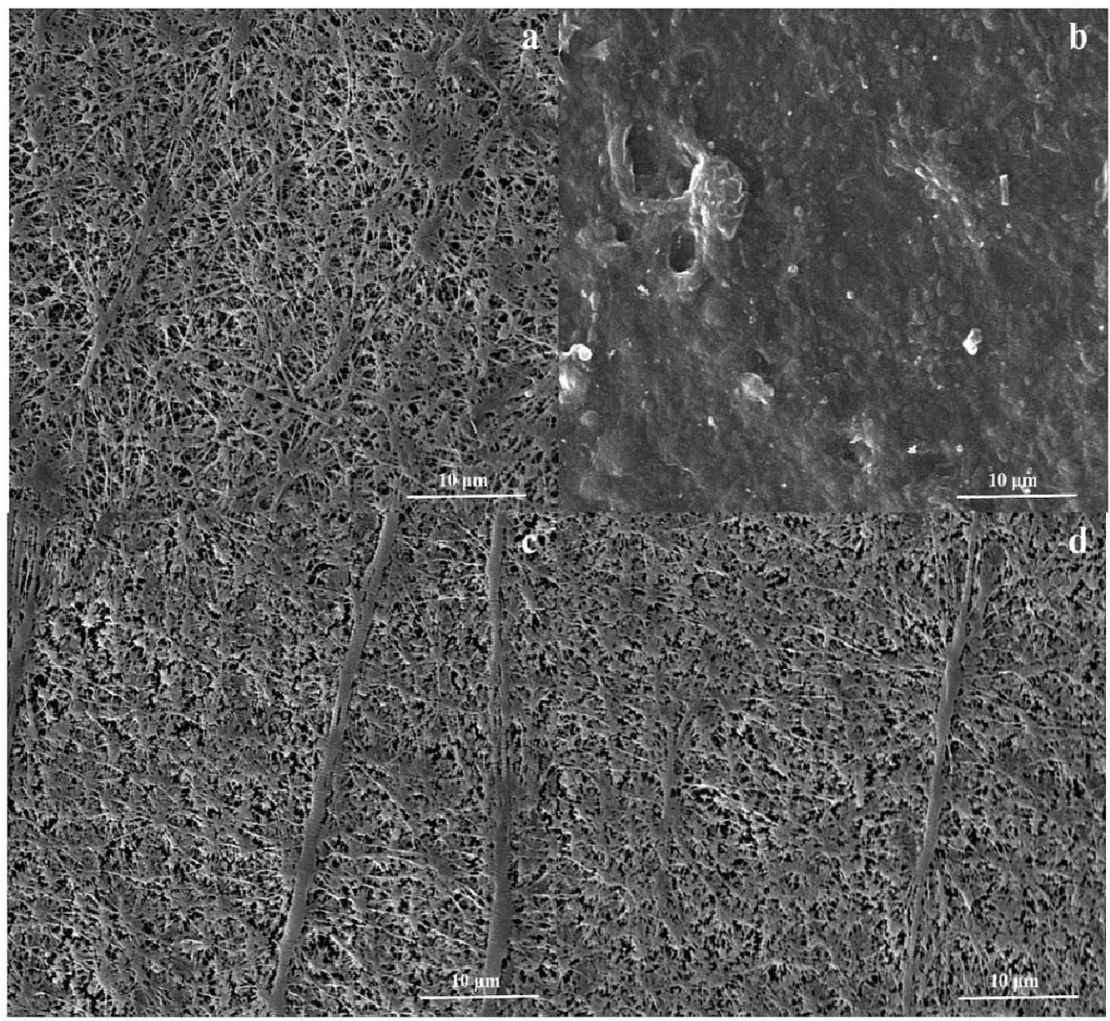

Fig. 7 SEM images of PTFE membranes: (a) original membrane, (b) fouled membrane, (c) fouled membrane cleaned with $\mathrm{NaClO}(0.04 \mathrm{~N})+$ $\mathrm{NaOH}\left(200 \mathrm{mg} \mathrm{L}^{-1}\right)$ mixed solution, and (d) fouled membrane cleaned with $\mathrm{HCl}(0.8 \%)$ solution. 


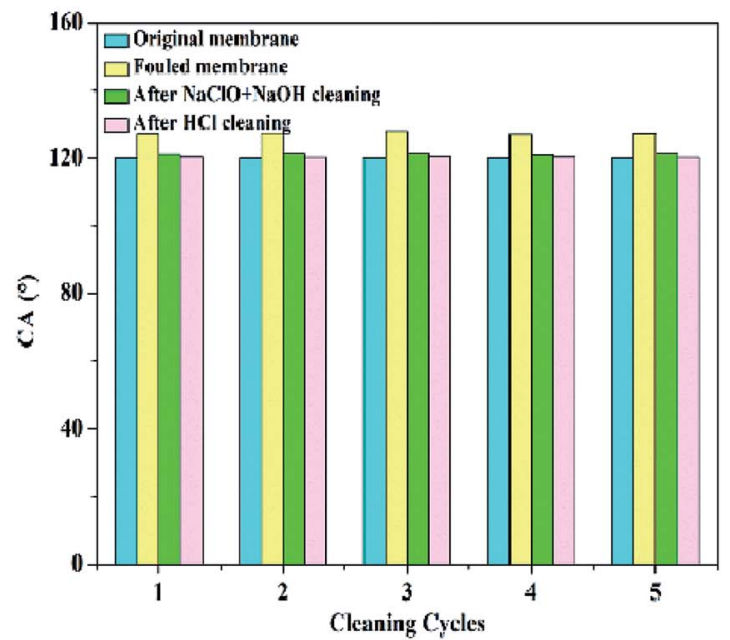

a

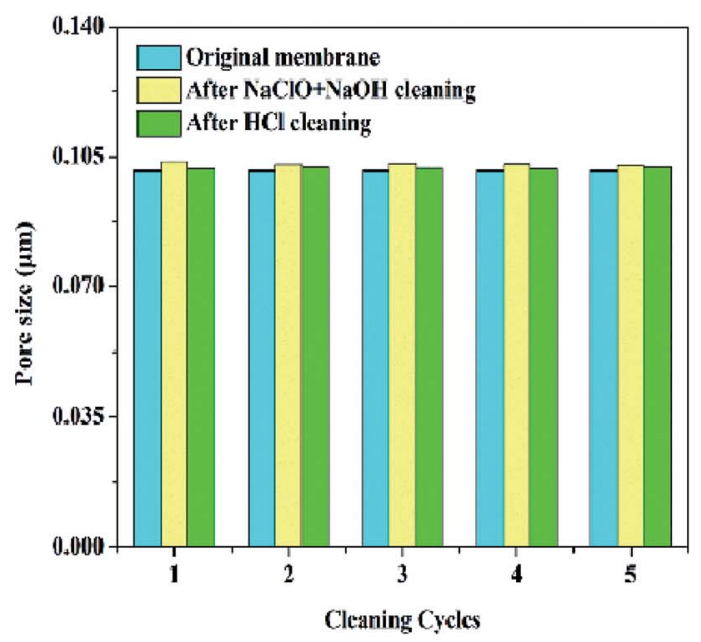

b

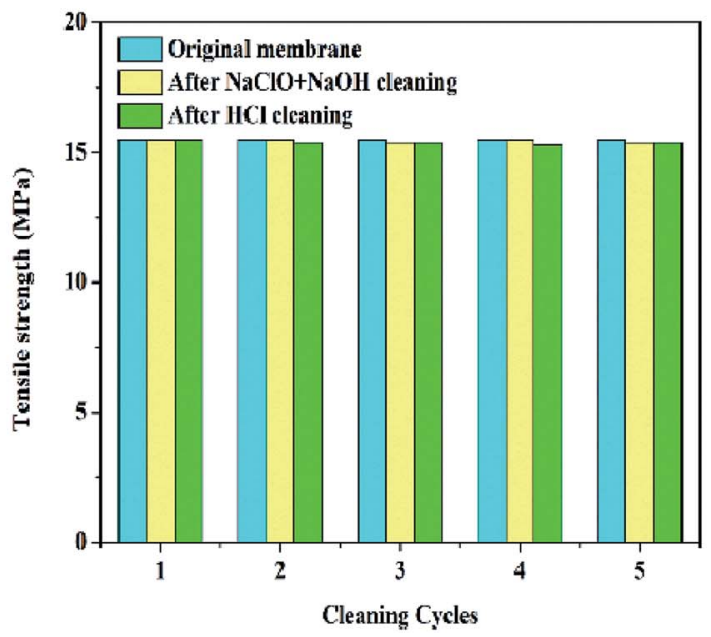

$\mathfrak{c}$

Fig. 8 Changes in membrane properties: (a) contact angle (CA), (b) pore size, and (c) tensile strength

(a)

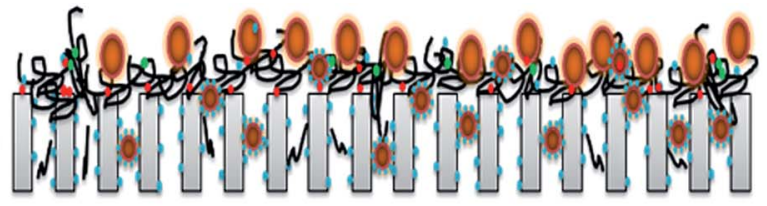

(b)

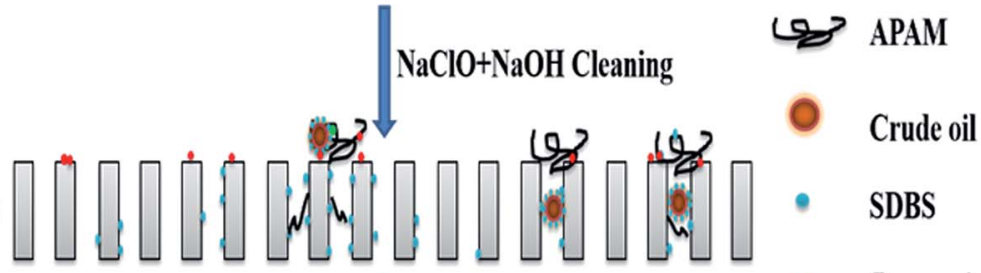

HCl Cleaning

Inorganic element (i.e., $\mathrm{Ca}, \mathrm{Mg}$ )

(c)

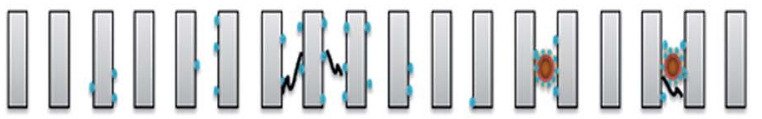

Fig. 9 Schematic of the proposed mechanism of chemical cleaning of the PTFE membrane for ASP flooding oilfield wastewater treatment. 
3.4.4 Proposed cleaning mechanism. The proposed mechanisms for the chemical cleaning of the PTFE membrane for ASP flooding oilfield wastewater treatment are depicted in Fig. 9. In the case of the coexistence of APAM and crude oil, APAM first bound to the membrane at a higher concentration with a faster migration speed, and the crude oil covered the surface of the APAM fouling layer. ${ }^{35}$ Due to high TDS in raw wastewater (Table S1 $\dagger$ ), the negatively charged APAM combined with oppositely charged ions, which weakened the intramolecular and intermolecular electrostatic repulsions in the APAM molecules; ${ }^{58}$ thus, APAM on the fouled membrane appeared curly (Fig. 9a). Moreover, inorganic elements, such as $\mathrm{Ca}$ and $\mathrm{Mg}$, could tightly bridge curly APAM to the membrane, making the fouling layer stronger. Furthermore, SDBS and precipitates were surrounded by foulants on the membrane and/or adsorbed on the inner wall of the membrane pores (Fig. 9a).

The microscopic analyses of the PTFE membranes (Fig. 3 and 7) revealed that consecutive cleaning with $\mathrm{NaClO}+\mathrm{NaOH}-$ $\mathrm{HCl}$ could effectively remove foulants from the PTFE membrane. During the $\mathrm{NaClO}+\mathrm{NaOH}$ cleaning process, $\mathrm{NaOH}$, primarily as a bulking agent and protein solubilizer, first attacked the outermost membrane fouling layer. Afterwards, $\mathrm{NaClO}$ reacted more easily with the innermost APAM. The crude oil, SDBS, and encapsulated inorganic precipitate on the APAM fouling layer were separated from the membrane as the inner layer of APAM disintegrated (Fig. 9b). The residual inorganic elements due to bridging were removed by $\mathrm{HCl}$ cleaning. Afterwards, the organic foulants connected with them fell off from the membrane (Fig. 9c).

\section{Conclusion}

In this study, foulant analyses, cleaning efficiencies of different reagents and conditions and mechanisms during MF of ASP flooding oilfield wastewater were studied. The following conclusions were drawn from the study:

(1) APAM and crude oil were the main membrane foulants accompanied by organic-inorganic-organic/membrane aggregate foulants formed by the bridging of inorganic ions.

(2) A cleaning efficiency of $93 \%$ was acquired through mixed cleaning with $0.04 \mathrm{~N} \mathrm{NaClO}+200 \mathrm{mg} \mathrm{L}^{-1} \mathrm{NaOH}$, which was found to be better than individual cleaning. Moreover, consecutive cleaning with $\mathrm{NaClO}+\mathrm{NaOH}-\mathrm{HCl}$ restored $98 \%$ of the membrane flux. Additionally, the cleaning temperature and time were set to $40{ }^{\circ} \mathrm{C}$ and $3 \mathrm{~h}$, respectively.

(3) SEM-EDX and FTIR analyses displayed that $\mathrm{NaClO}+$ $\mathrm{NaOH}-\mathrm{HCl}$ consecutive cleaning could effectively remove foulants from the membrane and restore membrane flux.

(4) The properties (CA, pore size, and tensile strength) of the cleaned membrane were not significantly different from that of the original membrane, which illustrated that the chemical properties of the PTFE membranes were relatively stable; also, consecutive cleaning using $\mathrm{NaClO}+\mathrm{NaOH}-\mathrm{HCl}$ was feasible.

\section{Conflicts of interest}

There are no conflicts to declare.

\section{Acknowledgements}

This work was supported by the National Key Research and Development Program of China (2016YFE0205600), National Natural Science Foundation of China (Grant No. 51778172), and the Innovation Group of New Technologies for Industrial Pollution Control of Chongqing Education Commission (CXQT19023).

\section{Notes and references}

1 B. Zhang, W. Shi, S. Yu, Y. Zhu, R. Zhang and J. Hwa Tay, J. Colloid Interface Sci., 2019, 544, 303-311.

2 Y. Zhu, S. Yu, B. Zhang, J. Li, D. Zhao, Z. Gu, C. Gong and G. Liu, Sci. Total Environ., 2018, 642, 988-998.

3 B. Zhang, S. Yu, Y. Zhu, W. Shi, R. Zhang and L. Li, RSC Adv., 2016, 6, 62411-62419.

4 A. Fakhru'l-Razi, A. Pendashteh, L. C. Abdullah, D. R. A. Biak, S. S. Madaeni and Z. Z. Abidin, J. Hazard. Mater., 2009, 170, 530-551.

5 J. M. Dickhout, J. Moreno, P. M. Biesheuvel, L. Boels, R. G. H. Lammertink and W. M. de Vos, J. Colloid Interface Sci., 2017, 487, 523-534.

6 Y. Zhang, Y. Xu, S. Zhang, Y. Zhang and Z. Xu, Desalination, 2012, 299, 63-69.

7 C. Li, H. Zhang, F. Wang, H. Zhu, Y. Guo and M. Chen, RSC Adv., 2019, 9, 19205-19216.

8 L. Ren, S. Yu, J. Li and L. Li, RSC Adv., 2019, 9, 11111-11122.

9 D. Wu, W. Zhou, X. Cheng, C. Luo, P. Li, F. Zhang and Z. Ren, RSC Adv., 2019, 9, 20035-20043.

10 A. Lin, S. Shao, H. Li, D. Yang and Y. Kong, J. Membr. Sci., 2011, 371, 286-292.

11 S.-C. Chen, S.-H. Lin, R.-D. Chien and P.-S. Hsu, J. Hazard. Mater., 2010, 179, 692-700.

12 B. Zhang, S. Yu, Y. Zhu, Y. Shen, X. Gao, W. Shi and J. Hwa Tay, Sep. Purif. Technol., 2019, 116212.

13 X. Sun, D. M. Kanani and R. Ghosh, J. Membr. Sci., 2008, 320, 372-380.

14 M. Peydayesh, T. Mohammadi and O. Bakhtiari, Sep. Purif. Technol., 2018, 194, 488-502.

15 S. Wang, K. Xiao and X. Huang, Sep. Purif. Technol., 2019, 210, 1008-1016.

16 Y. Chung, H. Kim, T.-S. Kim, Y. M. Kim and S. Kang, Sep. Purif. Technol., 2019, 219, 216-221.

17 W. Li, G. Ling, F. Lei, N. Li, W. Peng, K. Li, H. Lu, F. Hang and Y. Zhang, Sep. Purif. Technol., 2018, 190, 9-24.

18 J. Liu, K. He, S. Tang, T. Wang and Z. Zhang, Sep. Purif. Technol., 2019, 217, 118-127.

19 D. Zhao, L. Qiu, J. Song, J. Liu, Z. Wang, Y. Zhu and G. Liu, Sci. Total Environ., 2019, 652, 256-266.

20 G. Liu, L. Li, L. Qiu, S. Yu, P. Liu, Y. Zhu, J. Hu, Z. Liu, D. Zhao and H. Yang, J. Membr. Sci., 2018, 545, 348-357.

21 B. Zhang, W. Shi, S. Yu, Y. Zhu, R. Zhang and L. Li, RSC Adv., 2015, 5, 104960-104971.

22 J. Lindau and A.-S. Jönsson, J. Membr. Sci., 1994, 87, 71-78. 23 Y. Zhao, L. Hou and S. Yu, China Water \& Wastewater, 2013, 29, 134-137. 
24 Y. Song, B. Su, X. Gao and C. Gao, Desalination, 2013, 330, 61-69.

25 M. S. Manna, P. Saha and A. K. Ghoshal, RSC Adv., 2015, 5, 71999-72008.

26 Q. Li and M. Elimelech, Environ. Sci. Technol., 2004, 38, 4683-4693.

27 P. D. I. Fletcher, L. D. Savory, F. Woods, A. Clarke and A. M. Howe, Langmuir, 2015, 31, 3076-3085.

28 Z. Wang, J. Ma, C. Y. Tang, K. Kimura, Q. Wang and X. Han, J. Membr. Sci., 2014, 468, 276-307.

29 M. T. Khan, C.-L. d. O. Manes, C. Aubry and J.-P. Croué, Water Res., 2013, 47, 558-568.

30 M. T. Khan, M. Busch, V. G. Molina, A.-H. Emwas, C. Aubry and J.-P. Croue, Water Res., 2014, 59, 271-282.

31 M. Mouiya, A. Abourriche, A. Bouazizi, A. Benhammou, Y. El Hafiane, Y. Abouliatim, L. Nibou, M. Oumam, M. Ouammou, A. Smith and H. Hannache, Desalination, 2018, 427, 42-50.

32 M. M. Bazin, Y. Nakamura and N. Ahmad, J. Teknol., 2018, 80, 95-103.

33 H. Sun, H. Liu, S. Wang, F. Cheng and Y. Liu, Water Res., 2018, 146, 328-336.

34 J. Zhu, M. Tian, Y. Zhang, H. Zhang and J. Liu, Chem. Eng. J., 2015, 265, 184-193.

35 R. Zhang, W. Shi, S. Yu, W. Wang, Z. Zhang, B. Zhang, L. Li and X. Bao, Desalination, 2015, 373, 27-37.

36 H. Maekawa, G. Ballano, C. Toniolo and N.-H. Ge, J. Phys. Chem. B, 2011, 115, 5168-5182.

37 Y. C. Woo, J. J. Lee, L. D. Tijing, H. K. Shon, M. Yao and H.-S. Kim, Desalination, 2015, 369, 51-61.

38 Z. Zhang, M. W. Bligh, Y. Wang, G. L. Leslie, H. Bustamante and T. D. Waite, J. Membr. Sci., 2015, 475, 9-21.

39 A. L. Ahmad, N. H. Mat Yasin, C. J. C. Derek and J. K. Lim, J. Taiwan Inst. Chem. Eng., 2014, 45, 233-241.

40 X. Zhang, Q. Hu, M. Sommerfeld, E. Puruhito and Y. Chen, Bioresour. Technol., 2010, 101, 5297-5304.

41 X. Zhen, S. Yu, B. Wang and C. Liang, Water Wastewater Eng. Chinese, 2006, 32, 56-59.
42 C.-H. Wei, X. Huang, R. Ben Aim, K. Yamamoto and G. Amy, Water Res., 2011, 45, 863-871.

43 A. Grélot, C. Machinal, K. Drouet, A. Tazi-Pain, J. C. Schrotter, A. Grasmick and S. Grinwis, Water Sci. Technol., 2008, 58, 2041-2049.

44 N. Norazman, W. Wu, H. Li, V. Wasinger, H. Zhang and V. Chen, Sep. Purif. Technol., 2013, 103, 241-250.

45 A. L. Ahmad, N. H. Mat Yasin, C. J. C. Derek and J. K. Lim, Desalination, 2012, 302, 65-70.

46 A. El Achari, X. Coqueret, A. Lablache-Combier and C. Loucheux, Macromol. Chem., 1993, 194, 1879-1891.

47 C. Liu, S. Caothien, J. Hayes, T. Caothuy, T. Otoyo and T. Ogawa, in Proc. AWWA Water Qual. Technol. Conf., Denver Co., 2000, pp. 1-25.

48 M. D. Kennedy, J. Kamanyi, S. G. S. Rodríguez, N. H. Lee, J. C. Schippers and G. Amy, Adv. Membr. Technol. Appl., 2008, 131-170.

49 A. Al-Amoudi and R. W. Lovitt, J. Membr. Sci., 2007, 303, 428.

50 H. Liang, W. Gong, J. Chen and G. Li, Desalination, 2008, 220, 267-272.

51 X. Wang and T. D. Waite, Environ. Sci. Technol., 2009, 43, 9341-9347.

52 K. Xiao, Y. Shen and X. Huang, J. Membr. Sci., 2013, 427, 139149.

53 L.-F. Wang, D.-Q. He, W. Chen and H.-Q. Yu, Water Res., 2015, 81, 325-332.

54 S. S. Madaeni and S. Samieirad, Desalination, 2010, 257, 8086.

55 G. J. Zhang, Z. Z. Liu, L. F. Song, J. Y. Hu, S. L. Ong and W. J. Ng, Desalination, 2004, 170, 271-280.

56 M. Bartlett, M. R. Bird and J. A. Howell, J. Membr. Sci., 1995, 105, 147-157.

57 S. H. D. Silalahi and T. Leiknes, Desalination, 2009, 236, 160169.

58 G. Liu, S. Yu, H. Yang, J. Hu, Y. Zhang, B. He, L. Li and Z. Liu, Environ. Sci. Technol., 2016, 50, 1393-1402. 